\title{
"Nox", de Concha Urquiza, entre la noche del sentido y la noche oscura
}

\author{
Margarita León
}

El artículo analiza "Nox", considerado el último poema de Concha Urquiza (1910-1945), una de las poetisas religiosas más importantes de México. El poema, en última instancia, viene a ser una reflexión final sobre el proceso espiritual vivido como un fracaso por la escritora, debido a la imposibilidad de alcanzar la unión mística y conservar la fe. Siguiendo los diversos significados del símbolo de "Nox", de la "Noche", de acuerdo a la tradición mística, el artículo muestra cómo Urquiza lo utiliza y cómo lo confronta con su propia experiencia religiosa.

PALABRAS ClaVE: poesía religiosa y mística, poesía mexicana del siglo XX.

The paper analyzes "Nox", which is considered the last poem of Concha Urquiza (1910-1945), one of the most important religious poets of México. The poem is shown as a meditation about the spiritual process lived as a failure by the writer, due to her impossibility to approach the mystic union and to preserve faith. Following the different meanings of the symbol "Nox" - "Night", according to the mystic tradition-, the article shows how Urquiza uses and confronts it with her own experience. 

Margarita León

Instituto de Investigaciones Filológicas, UNAM

\title{
"Nox", de Concha Urquiza, entre la noche del sentido y la noche oscura
}

\author{
Daré mi ley en su mente, \\ y la escribiré en su corazón. \\ JEREMÍAS XXXI, 33
}

Concha Urquiza (Morelia, Michoacán, 1910) escribió los poemas de Nox, ${ }^{1}$ el mismo año de su fallecimiento (Ensenada, Baja California, 1945), por lo cual se constituyen en los últimos de su producción y, como la mayor parte de su poesía, se publicaron de manera póstuma. Por su forma poética, su contenido y su significación en el contexto de toda su obra, estos dos sonetos reunidos bajo un mismo título son una suerte de recapitula-

${ }^{1}$ Concha Urquiza escribió dos sonetos (I y II) a los cuales tituló con el nombre de "Nox", siguiendo - como en otras ocasiones - la tendencia de escribir varios poemas sobre un mismo tema o asunto, a veces como una serie, bajo un solo título. Es el caso de "Églogas del Pastor Nocturno" (1940) un largo poema en liras, constituido por cuatro partes, cada una con un subtítulo ("I. La campiña”; "II. El pastor"; "III. Los pastores"; "IV. Las pastoras"), aunque arropadas bajo un título general. Lo mismo sucede con "Las canciones del Cupatitzio" constituidas también por cuatro secciones ("I. Río abajo"; "II. Un mancebo"; "III. Un recuerdo"; "IV. Una variante"). Todos los textos citados o a los que aludimos son tomados de Concha Urquiza, Poesías y prosas. 
ción y conclusión de toda la vida de la autora, de su concepción religiosa y poética. ${ }^{2}$

Cuando escribe "Nox", Concha Urquiza lleva ocho años de haberse reconvertido al catolicismo de su infancia. ${ }^{3}$ También para entonces ha escrito toda la obra poética que hasta ahora se conoce, fundamentalmente la de corte religioso y místico. Está a la mitad de su vida adulta y su creatividad poética parece haber tocado su punto más alto. En esta etapa de su producción, su poesía es de reflexión más que de arrebato religioso; su estilo tiende hacia el perfeccionamiento formal dentro de los cánones y géneros clásicos (el soneto, la lira, la égloga), optando por la tendencia tradicionalista que se había desarrollado después del Modernismo y de las vanguardias poéticas y que se prolongaría durante la década de los cuarenta.

En efecto, Concha Urquiza se reafirma en el uso del soneto endecasílabo, siguiendo la preferencia de su cultivo durante el Siglo de Oro y que se prolongaría hasta el siglo xx. Como la mayoría de los poetas del periodo áureo (Garcilaso, Herrera, Góngora, etc.), la poetisa mexicana en su poema mantiene intacto el modelo tradicional en los dos cuartetos paroxítonos, de rima abrazada (ABBA; ABBA). En los tercetos hace lo mismo, pues se atiene al repertorio de variantes establecido desde entonces, al emplear una de las combinaciones más socorridas en la poesía española, es decir, CDC; DCD.

${ }^{2}$ Es importante señalar que "Nox" ha sido apenas comentado por articulistas y estudiosos, tocando su forma poética o aludiendo superficialmente a su contenido, a la luz de toda su obra. Hasta la fecha no se tiene noticia de poemas contemporáneos o posteriores a éste. Esto ha dado pie a que se le interprete como nota póstuma al supuesto suicidio de la autora, interpretación a todas luces inexacta.

${ }^{3}$ En una etapa significativa de su juventud, Concha Urquiza se acercó a la ideología socialista y comunista que circulaba a finales de los años veinte y principios de los años treinta en México. Tuvo amistad con los estridentistas —específicamente con Germán List Arzubide y Arqueles Vela—, quienes representaban, políticamente, el ala radical de la vanguardia mexicana. Ello significó un distanciamiento de la religión heredada de sus padres, aunque siempre conservando una actitud ética y mística respecto de ciertos valores, como la que tuvieron otros escritores e intelectuales de la época, influidos —entre otros factores— por las ideas vasconcelistas. 
Temáticamente, la poesía religiosa y mística de Concha Urquiza se reafirma en la profundización de las fuentes en donde abreva la literatura mística española: principalmente la Biblia, la poesía trovadoresca con su erotismo sublimado y la poesía pastoril clásica (Teócrito, Ovidio, Virgilio). En la producción de Urquiza de esa época, seguirá siendo predominante el asunto de su relación con Cristo, aunque ahora de manera más meditada, más lúcida y racional. Como otros poetas religiosos, la semilla del desencanto ha ido ganando terreno. Y es que vive en una duda constante respecto a su propia fe. Parece haberse convencido ya de que en un siglo y en una época signados por el escepticismo, ${ }^{4}$ cuando no por el pesimismo nihilista, ${ }^{5}$ es imposible tener una experiencia unitiva tan intensa como la que vivieron los místicos del pasado. Urquiza ha vivido más de ocho años de su vida adulta en una lucha constante y desgarradora contra su propia naturaleza, para alcanzar el estado beatífico que sólo es posible cuando se está en los brazos de Cristo, es decir, cuando el cuerpo muere. Ha sido para ella una noche tan larga y $\tan$ oscura que parece no tener fin.

El propio título de los textos referidos nos remite al significado del símbolo, pues Nox o Noche se contrapone al día; simboliza la oscuridad misteriosa de lo irracional o inconsciente, de la muerte, contraposición del seno materno que protege y da vida (Becker, Enciclopedia de los símbolos, 230). Las implicaciones psicológi-

${ }^{4}$ Siguiendo a Nicola Abbagnano (Diccionario de Filosofía), entiendo aquí por Escepticismo la tesis "que enuncia que es imposible decidir acerca de la verdad o falsedad de una proposición cualquiera" (424). El principio fundamental del escepticismo reza: "A toda razón se opone una razón de igual valor" (425), según creía Sexto Empírico. Dicho principio "impide tomar partido por una afirmación cualquiera o su negación y por lo tanto, permite mantener la imperturbabilidad" (425).

${ }^{5}$ Retomo Nihilismo en los términos de Nietzsche, quien afirma: "El N [...] no es solamente un conjunto de consideraciones acerca del tema: 'Todo es vano', no es sólo la creencia en que todo merezca perecer, sino que consiste en poner las manos en la masa, en destruir [...]. Es el estado de los espíritus fuertes y de las voluntades fuertes, a las cuales no les es posible atenerse a un juicio negativo: la negación activa responde mejor a sus naturalezas profundas" (Abbagnano, Diccionario, 854-855). 
cas y espirituales del símbolo de la noche en la poesía de Concha Urquiza son múltiples a lo largo de su producción y están presentes en estos sonetos. La noche remite al ambiente de oscuridad durante la espera amorosa y al sueño; representa implícitamente el cambio de estaciones vitales y espirituales en la vida humana, partiendo de la primavera (con su luz esperanzadora) hasta llegar al invierno (ligado a la decadencia y a la muerte); la noche es un estado del alma en la mística y se ha configurado - junto con la Subida y el Monte- en uno de sus símbolos centrales.

El primer poema de Nox dice:

Un soñar con el pálido ramaje y las llanuras donde cuaja el trigo, un aspirar a soledad contigo por los húmidos valles y el boscaje;

un buscar la región honda y salvaje, un desear poseerte sin testigo, un abrazado afán de estar conmigo viendo tu faz, en interior paisaje:

tal fue mi juventud más verdadera; en el clima ideal de tu dulzura maduró mi divina primavera;

y tuve mi esperanza tan segura, como que en la hermosura pasajera se me entregaba, intacta, Tu hermosura.

El segundo poema reza:

Como perdí, en estériles acasos, aquella imagen cálida y madura que me dio de sí misma la natura implicada en Tu voz y Tus abrazos 
Ni siquiera el susurro de Tus pasos, ya nada dentro el corazón perdura; te has tornado un "Tal vez" en mi negrura $\mathrm{y}$ vaciado del ser entre mis brazos.

Universo sin puntos cardinales, Negro viento del Génesis suplanta aquel rubio ondear de los trigales.

Y un vértigo de sombra se levanta allí donde Tus ángeles raudales tal vez posaron la serena planta. ${ }^{6}$

En una primera mirada, es posible observar que ambos poemas aluden al proceso espiritual experimentado por el yo lírico en dos momentos. En el soneto I, es el deseo, el anhelo lo que priva, la reiterada búsqueda de Dios; predomina una luz tenue, un entorno penumbroso, húmedo. En el soneto II, prevalece el desencanto, la desorientación y la oscuridad; ahora la violencia de un viento negro, "vértigo de sombra", contrasta con el aire suave que antes movía los trigales. Los verbos y las frases empleadas son más que ilustrativos. El "soñar", "aspirar a soledad contigo", "buscar", "desear poseerte sin testigo", da paso a la pérdida: "perdí en estériles ocasos", "ya nada [...] perdura", "te has vuelto un 'Tal vez' en mi negrura”.

El proceso espiritual es concebido como un movimiento nocturno, planteamiento derivado de la tradición escolástica medieval, que le llega a la autora a través de los místicos españoles, sobre todo vía san Juan de la Cruz. Dicho proceso consiste en que "la ordinaria visio-vespertina [...] puede convertirse en visio-matutina por medio de una fe iluminada y en una visio-meridiana en el cielo. El camino de tránsito de la tarde a la mañana, o mejor dicho, a la aurora, pasa, como es lógico, por

\footnotetext{
${ }^{6}$ Ambos textos provienen de Poesías y prosas, 127.
} 
la noche de la contemplación" (Hatzfeld, Estudios literarios sobre mística española).

Nox abarca dos tiempos distintos y contrastantes que dibujan lo que ha sido el tránsito de una condición vital y espiritual a otra. El yo lírico se sitúa en el presente, desde donde evoca no sólo nostálgica sino dolorosamente una etapa anterior cuando sueña, aspira, desea, busca el objeto amado, cuando hay cierta alegría porque hay esperanza, como lo expresa el soneto I. En un primer momento, se trata de un tiempo dominado por las tinieblas, por la penumbra, pero donde todavía es posible que la luz penetre. Es imposible no ver en estos versos alusiones - convertidas en metáforas- a pasajes específicos de la vida de Concha Urquiza. ${ }^{7}$ El primer terceto del poema I, a través de la frase "maduró mi divina primavera" y el contexto en el que aparece, hace referencia a los factores (disposición de ánimo, un primer contacto intuitivo o revelación de Dios) que intervinieron en la reconversión religiosa de Urquiza, esa "Primavera de 1937", "Primavera del alma", a la que continuamente alude en sus cartas, en su diario y que en el poema es sinónimo de una "juventud más verdadera". ${ }^{8}$

Ahora bien, la comparación en el poema urquiziano nos remite al concepto metafísico que establece una relación orgánica, estructural, entre ambos poemas. Los dos textos hacen referencia, muy al modo quevediano, a realidades que expresan de una forma peculiar los temas clásicos de la separación del espíritu y del cuerpo, el misterio de la unión de dos seres

\footnotetext{
${ }^{7}$ Desde edad muy temprana, la vida de Concha Urquiza se caracterizó por constantes crisis existenciales y espirituales, como bien puede comprobarse a través de las páginas de su diario y de sus cartas, así como por el testimonio del presbítero Tarsicio Romo, miembro de la orden de los Misioneros del Espíritu Santo, quien la conoce en 1937 por gestiones de Gabriel Méndez Plancarte.

${ }^{8}$ Una amplia explicación sobre lo que significó para Concha Urquiza esa "Primavera de 1937", cuando estaba sumida en una de sus crisis, está contenida en varias páginas de las "Meditaciones" o del "Diario" de la autora. Por ejemplo, la entrada correspondiente al 8 de diciembre de 1938 (Poesías y prosas, 222).
} 
en virtud del amor, la contingencia del hombre unida a su inmortalidad. ${ }^{9}$

Lo conceptuoso de los infinitivos utilizados, unidos al uso del hipérbaton, no debilita, sino enfatiza, la sensualidad y el erotismo del conjunto, característicos de la poesía de Urquiza y en general de la poesía mística. En el segundo cuarteto, los dos primeros versos hacen referencia a una virtual entrega de los amantes (el alma y Dios), aludiendo incluso a elementos que tienen una connotación sexual como la "región honda y salvaje" o "desear poseerte sin testigo". Los dos últimos versos en la estrofa conforman casi un silogismo: "un abrazado afán de estar conmigo / viendo tu faz, en interior paisaje". Tal declaración nos remite no sólo al deseo de silencio y de "soledad absoluta", sino a la idea de que Dios habita en el individuo, es inherente a él. Idea que se sale un tanto del canon místico, pues si bien la experiencia infusa de Dios se da en el interior del alma, la manifestación de la divinidad proviene de afuera, pues es otra su naturaleza. Y es que Dios, independientemente de nuestro deseo y voluntad, se manifiesta, se hace presente. Por ello es preciso "salir", dicen los tratados místicos cristianos, a buscar a Aquel que nos tocó, nos hirió con su flecha o su dardo, en aquella noche donde el alma estaba distraída.

La noche se concibe como "tránsito" temporal y espacial, el cual responde y se corresponde con el desarrollo de la propia experiencia mística. Se trata —afirma Ma. Jesús Mancho Duque - de "un proceso de conversión a lo divino, de un transformarse en Dios por participación" (Mancho Duque, Palabras y símbolos, 214). De acuerdo a la teología mística (san Juan

\footnotetext{
${ }^{9}$ En Quevedo el concepto "es la expresión de una correspondencia que realmente existe entre objetos diferentes y [...] puesto que el universo no es sino una red de correspondencias universales o de analogías que unen todos los elementos de la experiencia —aunque éstos sean aparentemente heterogéneos [...] las metáforas más heterogéneas son justificables" (Joseph A. Mazzeo apud Emilia Navarro de Kelley, "El concepto metafísico en Quevedo", 83).
} 
de la Cruz), la noche es un símbolo dinámico, pues implica un proceso de cambio, una transmutación de la propia naturaleza, es decir, el hombre viejo da paso al hombre nuevo (Mancho Duque, Palabras y símbolos, 215). Sin embargo la noche como tensión dialéctica entre ambos extremos, como expresión simbólica, alude más bien a la primera fase de esta transmutación, esto es, a la eliminación implacable del primer extremo; de ahí su carácter eminentemente negativo (Mancho Duque, Palabras y símbolos, 217). "La noche es un proceso que, mediante la negación gradual y progresiva en profundidad, genera la afirmación absoluta", sigue diciendo Mancho Duque. Y sin embargo, la noche como experiencia real conlleva al lado de factores negativos elementos positivos.

Lo positivo se concentra en la evocación casi panteísta del poema I, donde a través de la captación sensible de la naturaleza es posible ver la "faz" de Dios. Elementos como el "pálido ramaje", las llanuras fértiles, los valles "húmidos", el "boscaje", así como el ambiente umbroso y de soledad, ligan al poema con el locus amenus clásico, presente en la poesía mística. En una suerte de metáfora complementaria, el fondo del alma (interior paisaje) es un espejo donde se refleja la divinidad. La vista y el oído son los sentidos a los que se les da primacía, seguidos de las sensaciones que provienen del tacto y del gusto. El yo lírico se instala en la "noche pasiva de los sentidos"; 10

${ }^{10}$ Ma. Jesús Mancho Duque construye un esquema siguiendo las pautas dadas por F. Ruiz Salvador, en su Introducción a San Juan de la Cruz. El hombre, el escritor, el sistema (453), en las que las tres "noches" constituyen las diversas etapas del proceso místico, esto es, las llamadas "tres vías". El esquema parte de un "estado postbautismal no mencionado" y se siguen: 1) Vía purgativa, que consiste en la conversión o estado de los sujetos principiantes, los cuales experimentan "la noche activa de los sentidos" y luego la "noche pasiva de los sentidos" que es una fase de transición; 2) Vía iluminativa, que corresponde a los aprovechados, los cuales experimentan la "noche activa del espíritu" y la "noche pasiva del espíritu", que es una fase de transición; 3) Vía unitiva, que corresponde a la "Unión perfecta con Dios". El individuo ha pasado entonces por diversas etapas: Primera noche, Media noche, Despidiente; Antelucano (Mancho Duque, Palabras y símbolos, 220 y 221). 
esto es, aquella que corresponde a lo más sensible, material o exterior de la actividad psicológica del sujeto (Mancho Duque, Palabras y símbolos, 219).

Como en el resto de su obra religiosa, desde los poemas de 1937 hasta los de la década de los cuarenta, en Nox Concha Urquiza recurre como a un surtidor inagotable de imágenes a la idea platónica del amor y al mito clásico de Narciso que han cuajado en el tópico poético "del amante que asegura o acredita — señala José Manuel Pedrosa— que lleva impreso en su ardoroso corazón el retrato de su amada". ${ }^{11}$ En la literatura devota y en la poesía mística, principalmente en la de san Juan, el mito y el tópico poético se retroalimentan a su vez del tema bíblico, convirtiéndose en un símbolo: el "alma-espejo", que refleja el rostro amado de Dios. ${ }^{12}$

A pesar de que el discurso urquiziano queda enmarcado en la convención teológica y retórica de la poesía religiosa y mística, el soneto II de Nox presenta algunos desvíos. Respecto a lo primero, algunos versos tienen su raíz en temas y tópicos característicos de la poesía de los Siglos de Oro (renacentistas y barrocos), que a su vez ésta retoma de los textos clásicos y de la poesía medieval. Por ejemplo, están presentes elementos que provienen de la retórica del amor cortés dirigidas a lo divino. El tono es el de la reflexión, uno eminentemente intelectual, lúcido, desencantado. En este sentido se percibe cierto realismo, propio de una intimidad más familiar y más emotiva, aunque

\footnotetext{
${ }^{11}$ En su puntual e interesante estudio sobre el tema, José Manuel Pedrosa señala que esta creencia aparece ya en la Biblia (Proverbios III, 3; Jeremías XXXI), aunque enfocada hacia el amor divino y no hacia el humano. Apunta además que, en la concepción del amor en la Edad Media y en los Siglos de Oro, la idea de que la amada es capaz de quedar impresa o dibujada en el amado tiene sus posibles antecedentes en diversos diálogos platónicos, y es un tópico poético que desarrollaron muchos escritores, entre ellos Petrarca en su Canzoniere ("Miguel de Cervantes, John Donne y una canción popular", 71-92).

${ }^{12}$ Denis de Rougemont, señala entre los principales temas comunes a los trovadores y a los místicos ortodoxos en 'El simbolismo del 'espejo', amor imperfecto que remite al amor perfecto" (El amor y occidente, 164).
} 
sin renunciar al conceptismo en su contenido ("Ni siquiera el susurro de Tus pasos, / ya nada dentro el corazón perdura"). La desaparición absoluta de ese entorno natural — semioscuro, húmedo y tibio-, que ahora sólo es evocado, hace más dolorosa su pérdida. Las frases "Como perdí... aquella imagen cálida y madura", o "Negro viento... suplanta aquel rubio ondear de los trigales", señala el cambio radical que se ha verificado. Ahora bien, el yo lírico vive un presente de absoluta oscuridad, sequedad y silencio; por ello sólo cabe un lamento prolongado por la pérdida de lo que se vislumbraba como Paraíso "posible", lugar utópico construido por la esperanza.

Desde la preceptiva mística, el yo lírico en el poema II de Nox ha transitado de la "Noche del sentido" en su fase activa, a la "Media noche", "Noche del medio" o "Noche de la fe". Es esta noche la última etapa intermedia entre aquélla — la del sentido_ y la llamada "Noche del espíritu" en la cual se da la unión definitiva del alma y Dios. La medianoche en la tradición mística es descrita como la más oscura y la más dolorosa de las tres, pues es la noche donde la luz "está tan remota", más incluso que el "antelucano", momento que precede a la luz del día, pues — dice san Juan de la Cruz- "ya está inmediata a la ilustración e información de la luz del día, y ésta es comparada a Dios" (Juan de la Cruz, Cántico Espiritual, 2, 1). La "noche del medio" es percibida por el místico como la más profunda y oscura, "porque sucede sin el auxilio de la razón, y la lumbre sobrenatural aún no es tolerable para el alma" (Mancho Duque, Palabras y símbolos, 220). El poema de Urquiza describe puntualmente dicha experiencia o estado espiritual, pero situándose en una suerte de "fase de transición" hacia la noche oscura (Mancho Duque, Palabras y símbolos, 221). Lo dramático, sin embargo, es que dicha fase no le asegura el tránsito a esa otra noche donde el alma y Dios se vuelven uno solo, sino la conducen, en un movimiento de eterno retorno, al mismo sitio, el de la duda. 
Luego de un primer momento de mea culpa por la pérdida de la "imagen cálida y madura" de Dios, viene la afirmación, en signo negativo, de su ausencia absoluta. De éste, reconoce el yo lírico, "nada perdura" dentro, ni siquiera un susurro, la voz, el discurso, la imagen. La historia del paso de Cristo en la tierra, contenida en los Evangelios, no resuena en el corazón. En medio de tan completa oscuridad, no hay reflejo alguno de su existencia ("Te has tornado un 'Tal vez' en mi negrura"). La experiencia humana, desprovista de imágenes, se anula totalmente, se vacía de sentido. El debate que se vislumbra en el poema, la preocupación que subyace a la elección y a la disposición de los elementos en todos los niveles del poema, expresados en la relación presencia-ausencia de Dios, es el de la fe. ${ }^{13}$

Siguiendo a san Juan de la Cruz, la poetisa mexicana sabe o intuye como todo místico que "sólo mediante el oscurecimiento voluntario del entendimiento propio es posible adentrarse en la luz tenebrosa de la fe, como condición sine qua non", de ahí que la fe emerge - señala Mancho Duque- "como florecimiento de la sombra profunda, a manera de luminiscencia abisal, al igual que la narración bíblica del Génesis" (Mancho Duque, Palabras y símbolos, 227). El tema de la fe y su contraparte, el de la duda, aparecen en el poema de Urquiza a través de la metáfora "Negro viento del Génesis", que remite a los versículos que corresponden a la creación del mundo y que describen: uno, la tierra y los cielos tomaron un lugar en el espacio, pero no forma y contenido; dos, la oscuridad; tres, la profundidad acuosa dentro del espacio sin forma; cuatro, el viento sobre la superficie de las aguas. El viento en el texto sagrado corresponde al Espíritu de Dios. Dice el versículo 2:

${ }^{13}$ Desde la preceptiva mística el hecho de que el alma (el yo lírico en el poema) se encuentre carente de visión y de luz, por lo cual no puede tener una imagen de Dios, la acerca al objetivo final que es la "Noche del espíritu", donde la "potencia visiva" — que se extiende a toda la persona — queda totalmente anulada, "para permitir que el alma se encamine hacia la infusión de la luz divina, la cual, como fosforescencia abisal, sólo emerge de la tiniebla" (Mancho Duque, Palabras y símbolos, 222). 
Y la tierra estaba desordenada y vacía y las tinieblas estaban sobre la faz del abismo, y el Espíritu de Dios se movía sobre la faz de las aguas (La santa Biblia, 5).

El yo lírico parece tener en mente este pasaje, haciendo énfasis en la falta de orden y dirección, de luz y de forma que privaba en el momento de la Creación, situación que, implícitamente, compara con su propio estado espiritual. La oscuridad, la desorientación que provoca el vértigo causado por el negro viento del espíritu de Dios se instala en el alma. Todo ello se le presenta al yo lírico como inspiración para los dos últimos tercetos que describen las consecuencias de la muerte de Dios, la cual, sin embargo, no se presenta en la forma en la que Nietzsche la entiende, pues para el filósofo "lo que ha muerto es la idea monoteísta de Dios" (Savater, Nietzsche). La muerte de Dios en el alma es la duda perpetua no sobre su existencia, sino sobre la fe que la hace posible. Hasta aquí parece que todo lo expresado en el poema es totalmente coherente con la tradición mística cristiana a la que se afilia Urquiza. Sin embargo, hay elementos que hacen pensar en que hay un ligero pero significativo desvío respecto de la ortodoxia.

Uno de esos elementos se encuentra en la vacilación contenida en expresiones como "Ni siquiera", "Ya nada" o "Tal vez", las cuales se combinan con otras que hacen referencia a la pérdida, pero también tienen que ver con una reflexión que encuentra su núcleo en el verso: "y vaciado del ser entre mis brazos". Tal enunciado remite a la pérdida del sentido de Dios.

Si bien en el poema se admite la idea de santo Tomás de Aquino, quien afirma la necesidad del ser divino como identidad en la esencia y la existencia en Dios (Mancho Duque, Palabras y símbolos, 334); si bien con san Agustín, se cree que Dios es el creador de todo lo que es, quien "sacó del no ser al ser", parece que ese poder ha sido insuficiente. La fe ejerce una purificación a través del oscurecimiento voluntario 
del entendimiento. La evocación o recordatorio constante de lo luminoso, de las imágenes del mundo, "aquel rubio ondear de los trigales", aun en medio de la oscuridad y el espanto del vértigo, se acercan peligrosamente a un gnosticismo — quizá inconsciente-, específicamente a la teoría del dualismo que aspira a la unión de los dos principios supremos del bien y del mal, para engendrar al mundo, en el cual se unen las tinieblas y la luz, aunque con preponderancia de las tinieblas (Abbagnano, Diccionario de filosofía, 590). Desde esta perspectiva, la noche de la fe se revela entonces como una aspiración del sujeto de llegar a ese día en que se contemplará a Dios cara a cara, pero llevando consigo su naturaleza compleja y contradictoria, toda su humanidad.

Los dos sonetos que constituyen "Nox" son el testimonio del tortuoso proceso espiritual que vivió Concha Urquiza a lo largo de varios años y, en un sentido, de la historia de un fracaso: la imposibilidad de lograr la anhelada unión mística y más, de mantener viva la fe en Dios. La aceptación de esta verdad, nos dice a través de sus versos la autora, por momentos pareciera arrastrarla al escepticismo. Esto ha llevado a que el poema sea interpretado, temerariamente, como una especie de nota póstuma previa a un supuesto suicidio. Por el contrario, la lectura atenta del mismo, en el contexto de su vida y de su obra creativa, revela que en Urquiza pudo más la solidez de sus convicciones religiosas y, del otro lado, su fidelidad a la tradición mística española (san Juan de la Cruz) que informa su obra. 


\section{REFERENCIAS}

Abbagnano, Nicola, Diccionario de Filosofía, México, Fondo de Cultura Económica, 1982.

BECKER, Udo, Enciclopedia de los símbolos. La guía definitiva para la interpretación de los símbolos, trad. José Antonio Bravo, México, Océano, 7a. reimp., 2001.

Fell, Claude, José Vasconcelos. Los años del águila, México, Universidad Nacional Autónoma de México, 1989.

HatzFeld, Helmut, Estudios literarios sobre mística española, Madrid, Gredos, 1955 (Biblioteca Románica Hispánica, II. Estudios y Ensayos).

Juan de la Cruz, San, Cántico Espiritual. Poesías, Cristóbal Cuevas García (ed., estudio y notas), Madrid, Alhambra, 1979.

La santa Biblia (Antiguo y Nuevo Testamento), México, Sociedades Bíblicas en América Latina, 1960.

Mancho Duque, Ma. Jesús, Palabras y símbolos en San Juan de la Cruz, t. 23, Madrid, Fundación Universitaria Española-Universidad Pontificia de Salamanca, 1993 (Espirituales Españoles, Serie C, Monografías).

Navarro de Kelley, Emilia, La poesía metafísica de Quevedo, Madrid, Guadarrama, 1973 (Colección Universitaria de Bolsillo, Punto Omega 155).

Pedrosa, José Manuel, "Miguel de Cervantes, John Donne y una canción popular", Acta Poetica, 26: 1-2, 2005, 71-92.

Rougemont, Denis de, El amor y occidente, trad. Mónica Pániker, Barcelona, Kairós, 1979.

Ruiz Salvador, Federico, Introducción a San Juan de la Cruz. El hombre, el escritor, el sistema, Madrid, Biblioteca de Autores Cristianos, 1968.

SAVATER, Fernando, Nietzsche, México, Universidad Nacional Autónoma de México, Facultad de Filosofía y Letras (Seminario de Metafísica)-Aquesta Terra Comunicación, 1993 (Alebrije).

Teresa de Jesús, SAnta, Las Moradas, Buenos Aires, Espasa-Calpe 1939 (Austral, 86).

URquiza, Concha, Poesías y prosas, Gabriel Méndez Plancarte (pról.), Guadalajara, Editorial El Estudiante, 2a. ed., 1971. 